\title{
Can Global Software Teams Learn From Military Teamwork Models?
}

\author{
Elizabeth J. Hargreaves, Daniela E. Damian \\ University of Victoria, BC, Canada \\ \{elizabeth.hargreaves, danielad\}@cs.uvic.ca
}

\begin{abstract}
Examining a domain outside of traditional software development may provide opportunities to address the challenges faced by global software teams. In this position paper, we examine the military model since its spirit of cooperative teamwork is well known and clearly documented. Specifically, we explore how an underlying code of conduct and the reinforcing subculture can create highly cohesive, effective teams. Referring to military models in order to build civilian teams is not without historical precedent; we hope that this investigation will prove fruitful. Ultimately, we seek to discover the qualities of the exceptional global software developer while exploring what we believe to be a rich research opportunity.
\end{abstract}

\section{Introduction}

A critical success factor for military teams is the underlying ethos that governs the interactions between team members. Dangerous working conditions and high stress levels require these teams to meet positive stereotypes of being honest, hard-working, disciplined and loyal (Feaver and Kohn, 2001). Furthermore, military organizations intentionally develop a distinct subculture to facilitate communication and minimize conflict between individuals from disparate backgrounds, including cultural differences within national boundaries. In contrast, global software development (GSD) teams experience challenges specifically related to teamwork and cultural differences.

This paper intends to stimulate further research into ways in which GSD research can learn from models of military teamwork and which may possibly benefit civilian GSD teams. Note that an examination of the weaknesses and problems inherent to military organizations is considered outside the current scope; in addition, the idealistic nature of this paper is readily acknowledged. For our purposes, we assume that the demands placed on GSD teams differ significantly from those experienced by collocated teams. A GSD team itself is understood to include individuals who rely on computer-mediated communication tools in order to collaborate across significant geographic boundaries.

Military values are typically impressed upon recruits during initial induction and can become an intrinsic part of professional and personal identity. The justification for this philosophy of cooperative teamwork is group survival - with the distinction between the individual versus the group often being ignored. With varying degrees of effectiveness, military organizations coordinate the activities of thousands of people on a global scale and dynamically form new teams on a regular basis. Relying on an established interaction framework that every individual knows, teams can quickly be built from a selection of complete strangers. While this framework may seem impersonal, it can also create a highly productive work environment that prioritizes cooperation over interpersonal politics.

Research shows that GSD teams experience challenges relating to trust, communication, conflict and cultural differences (Damian and Zowghi, 2003; Herbsleb and Moitra, 2001; Oppenheimer, 2002). For example, GSD teams have few opportunities to benefit from the advantages of informal communication. Geographic distances make it harder to establish and maintain interpersonal relationships critical to teambuilding. Subsequently, cross-site negotiations are often characterized by extreme caution in making commitments; in particular, it is harder to trust a remote colleague's arguments, to "see the value of a person" and to anticipate and resolve conflicts at a distance (Damian and Zowghi, 2003). In addition, global teams rarely agree upon communication practices or development processes in which project roles are clearly and well defined at the beginning of the project (Paasivaara, 2003). Many GSD teams operate within corporate environments which thrive on a 'survival of the fittest' mentality with competition between team members often being intentionally fostered by management. Due to this attitude, the 'enemy' can in fact be one's closest team members; as a result, GSD 
team members may face the additional overhead of protecting themselves from their own team.

In many ways, military teams face challenges similar to their GSD counterparts. For example, naval teams communicate using radio or satellite technologies across huge distances for months at a time with colleagues they may have never met in person. Interactions between coworkers are regulated by a known code since a previously established relationship of trust and accountability cannot be assumed. Undoubtedly, not all military teams function effectively, and sometimes with disastrous results. However, in the interests of productivity and efficiency within the context of GSD, it may be worthwhile to examine the characteristics of successful teams outside the corporate sphere. This exploration is simplistic and not intended to cover the topic extensively; instead, we hope to foster discussion and encourage further research. In the following sections we intentionally consider only two of the potential success factors of military teams.

\section{Code of Conduct}

Military organizations, such as the American army, rely on codes of conduct as the foundation of teambuilding. Simplistic versions of these codes are typically found in many forms of military literature. The US Army describes itself as: "It's having individual strength and the support of an unstoppable team." [1] The US Soldier's Creed places an emphasis on singlemindedness and accountability for teammates as a critical part of the military ethos: "I will always place the mission first./ I will never accept defeat./ I will never quit./ I will never leave a fallen comrade." [2] How closely the code is followed is, in a sense, a measure of the level of professionalism achieved. Despite an uncertain level of confidence in the military overall, Americans continue to consider their soldiers to be the most highly respected professionals in the country (Feaver and Kohn, 2001).

While professionalism is undeniably important within corporate spheres, the corresponding conduct is often ambiguous and can change dramatically based on context. Shifting mores within the field of GSD can be particularly problematic when faced with the previously mentioned challenges of reduced trust and ambiguous communication. Furthermore, the professional responsibilities of software developers remain in embryonic form since a comprehensive code of conduct for software developers is still developing. Personal reputations are frequently based on technical expertise as opposed to an ability to ensure the success of fellow team members or a high level of personal integrity. High turnover and unstable markets no doubt also contribute to shifting allegiances and a diminished sense of loyalty.

\section{Military Subculture}

Military codes of conduct are reinforced by the surrounding subculture. Stripped of the financial and professional incentives found in corporate environments, soldiers have fewer motivations to work against one another. Known pay scales and the rigidity of the rank system do not provide an equivalent opportunity for advancement and reduces competition among peers. Furthermore, the vertical chain of command and a visible hierarchy simplifies communication between coworkers. Informal communication is also highly influenced by this subculture-slang, jokes and topics commonly discussed within the military environment contribute to creating cohesive teams.

In contrast, corporate environments provide a lot of opportunity for 'leapfrogging' over colleagues while corporate secrecy permits negotiable salaries. Invisible hierarchies within corporate environments (exacerbated in global software teams) often result in personnel devoting a significant amount of time negotiating political minefields instead of working productively. While a software subculture certainly exists, interactions with others are not necessarily based on principles of trust and integrity, nor is there a consistent level of personal accountability for other team members.

\section{Conclusion}

In this paper we encouraged approaching current challenges in global software teams by learning from the critical success factors found in military teamwork models. We believe that cooperation is an undeniably critical dimension of GSD and suggest that a reinforced sense of teamwork may enable team members to overcome GSD challenges. Specifically, we seek to examine how a defined code of conduct and supporting subculture may allow team members to overcome problems related to trust, communication, conflict and cultural differences.

The challenges faced in GSD are not unique from an organizational perspective. Referring to military models to build civilian teams has significant historical precedent. Police, paramedical and fire-fighting units are examples of civilian organizations that successfully leverage military techniques in order to build successful teams. Can GSD teams use these same techniques? Note that we are not trying to create a platoon of programmers; instead, we wish to simply adopt the positive traits found in 
military teams. In addition, we do not expect that the same level of discipline found in military environments would be necessary within the software domain. Finally, if military teambuilding techniques are successfully adopted, is there a research opportunity to develop tools and methodologies to support it? Ultimately, we seek to identify the characteristics of the exceptional global software developer. We also strive to determine how to develop and nurture these same traits in individual developers in order to build highly effective GSD teams.

\section{References}

Damian, D. and Zowghi, D. "RE challenges in multi-site software development organizations", Requirements Engineering Journal, 2004.

Feaver, P.D. and Kohn, R.H. "Uncertain Confidence: Civilian and Military Attitudes About Civil-Military Relations", Soldiers and Civilians: The Civil-Military Gap and American National Security. MIT Press, Cambridge, 2001.

Herbsleb, J. and Moitra, D. "Global software development”, IEEE Software, March/April, 16-20, 2001.

Oppenheimer, H. "Project management issues in globally distributed software development", Proc. International Workshop on Global Software Development, 2002.

Paasivaara, M. "Communication Needs, Practices and Supporting Structures in Global Inter-Organizational Software Development Projects", Proc. International Workshop on Global Software Development, 2003.

[1] "What is the US Army?" GoArmy.com - Army 101. United States Department of Defense.

http://www.goarmy.com/army101/index.htm. Accessed Mar 212004.

[2] "The Soldier's Creed". Our Army At War - Relevant and Ready. United States Department of Defense. http://www.army.mil/thewayahead/creed.html. Accessed Mar 212004. 